\title{
Analysis of Post-Obstetric Surgery Referrals with Surgical Complications to Tertiary Hospital in Indonesia
}

\author{
Khoirunnisa Novitasaria ${ }^{a}$, Hanifa Erlin Dharmayantib, Baksono Winardic ${ }^{\mathrm{c}}$, Brahmana \\ Askandar Tjokroprawiro ${ }^{\mathrm{d}}$, Budi Prasetyo ${ }^{\mathrm{e}}$
}

\begin{abstract}
${ }^{a}$ Obstetrics and Gynecology Resident of Airlangga University, dr. Soetomo Teaching Hospital, Surabaya 60115, Indonesia ${ }^{b}$ Obstetrics and Gynecology Department Staff of Airlangga University, dr. Soetomo Teaching Hospital, Surabaya 60115, Indonesia ${ }^{c}$ Obstetrics and Gynecology Department Staff of Airlangga University, dr. Soetomo Teaching Hospital, Surabaya 60115, Indonesia ${ }^{d}$ Obstetrics and Gynecology Department Staff of Airlangga University, dr. Soetomo Teaching Hospital, Surabaya 60115, Indonesia ${ }^{e}$ Obstetrics and Gynecology Department Staff of Airlangga University, dr. Soetomo Teaching Hospital, Surabaya 60115, Indonesia
\end{abstract} Corresponding author : khoirunnisa.novitasari-2016@fk.unair.ac.id

\begin{abstract}
Recently, the high rate of C-section is caused by obstetric indications and large number of elderly pregnant patients with maternal complications and fetal continuous monitoring use. $\mathrm{C}$-section has higher risk of complication than vaginal delivery. Some post obstetric surgery complications require aggressive measures such as relaparotomy on critical conditions that cause morbidity.

This retrospective study will analyze the profile of post-obstetric surgery referrals with surgical complications to Dr. Soetomo General Teaching Hospital. The records were total sampling according to inclusion and exclusion criteria using medical record data in 2019-2020.

There were 27 cases of post-obstetric surgery referrals with surgical complications from all 70 post-obstetric surgery referrals (38.5\%) - most referrals from outside Surabaya by private hospitals. Most patients were in 21-35 years (74\%), $51.85 \%$ multiparity, only $18.5 \%$ with obesity. Most of the patients came with hypovolemic shock and complications of thrombocytopenia, prolonged haemostasis, and acute renal impairment. Most common indications for referrals are internal bleeding and postpartum hemorrhage. Operations at the referring hospital were performed emergency in $77.7 \%$ of cases. The most indications for surgery that increased the risk of relaparotomy were previous $\mathrm{C}$-sections and the arrest of labors. Relaparotomy was performed in 23 cases $(83.1 \%)$, most common findings were bleeding from the corner stitch of uterine incision and retroperitoneal hematoma. Most common procedures during relaparotomy were hysterectomy $42.42 \%$ and vascular ligation $30.3 \%$.

Relaparotomy on post obstetric surgery referrals was performed in patients with suspicion of internal bleeding due to bleeding from corner stitch of uterine incision and indications for surgery that were risk factors for relaparotomy were previous caesarean section and arrest of labors
\end{abstract}

Keywords: referrals; caesarean section; surgical complications

\section{Introduction}

Caesarean section is the most common obstetric surgery carried out in daily obstetric practice. In many countries there has been dramatic rise of caesarean section rate over 50 years. It caused by elderly pregnant patients with various maternal complications and fetal continuous monitoring use (Biswas et al., 2012). Caesarean section has a three times higher risk of complications than vaginal delivery (Peket et al., 2019). This may depend on variation of quality of surgery, institutional facilities and also underlying pathology for indication of operation. Some post-surgery complications require aggressive measures on critical conditions such as relaparotomy.

Relaparotomy is a procedure of opening the abdomen in conditions that require exploration performed within sixty days postpartum. The relaparotomy rate after caesarean section ranges from 0.12 to $0.72 \%$. The most 
common indications for relaparotomy in post-obstetric surgery cases are suspicion of internal bleeding, postpartum haemorrhage, suspicion of surrounding organ injury and sepsis (Peker et al., 2019). Relaparotomy has also had a risk that may increase maternal morbidity and mortality.

Not all post-obstetric surgery referral patients with complications underwent relaparotomy immediately when diagnosed. Some cases have to be referred to a tertiary hospital due to limited resources and medical facilities. These problem will affect the patient's condition and prognosis. The quality of obstetric services including management of surgery complication will affect to increased maternal morbidity and mortality. In this study, all maternal cases of post obstetric surgery with complication which referred to Dr. Soetomo General Teaching hospital as tertiary hospital due to their surgery complication will be reviewed to identify problems that may interfered.

\section{Methods}

This research is an analytical retrospective study in Dr. Soetomo General Teaching Hospital in 2019-2020 using medical records data. It reviewed all post obstetric surgery referral patients with surgical complications who met the inclusion criteria. The inclusion criteria were all cases of post-obstetric surgery referral (cesarean section or caesarean hysterectomy) with surgical complications such as postpartum hemorrhage, suspicion of internal bleeding to Dr. Soetomo General Teaching Hospital from January 2019 - December 2020. The exclusion criteria were post-obstetric surgery referral patients with complications that have exceeded the time limit, which is more than sixty days since the first operation or is not referred cases. The main characteristics measures of the study were demographic profile of the referral cases, including the area of referrer origin, age, parity, obesity status, referral time, and referral indications, patient GCS, blood pressure, ventilator use, hemoglobin levels, platelets, prolongation of hemostasis function, and acute renal impairment. The case profile includes indications of surgery at the referring hospital, types of procedures (emergency/elective), indications for relaparotomy, findings during relaparotomy and surgical procedures performed during relaparotomy in Dr. Soetomo General Teaching Hospital.

\section{Result}

We found 70 cases of post-obstetric surgery referrals to Dr. Soetomo General Teaching Hospital during 2019-2020. Twenty-seven cases with surgical complications (38.5\%) and 23 cases requiring relaparotomy (85.1\%). We recorded 13 cases in 2019 and 14 cases in 2020. The highest incidence of referral cases with surgical complications was in December 2020.

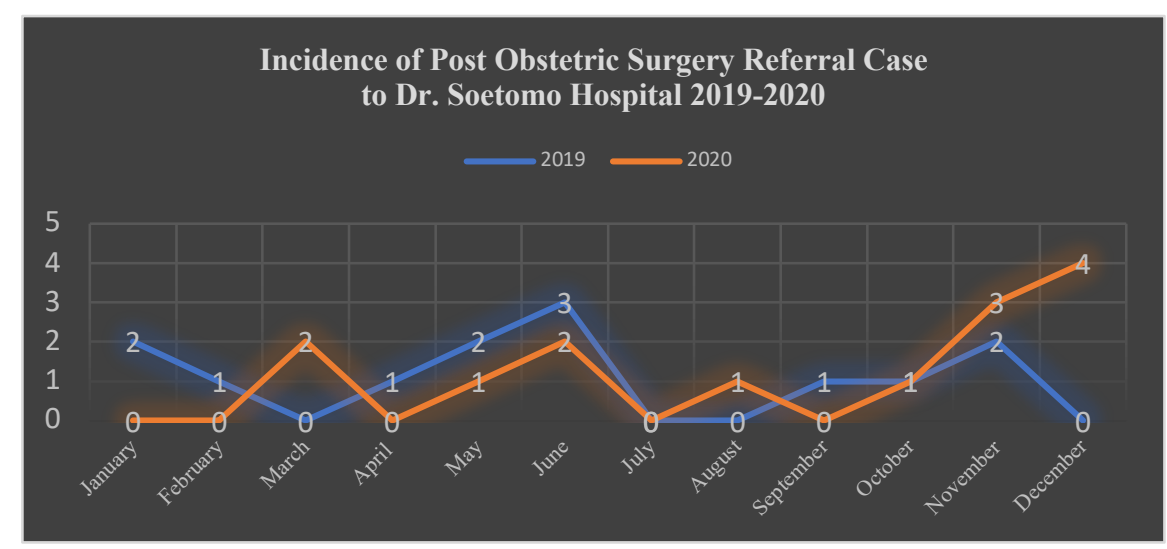


Figure 1. Incidence of Post Obstetric Surgery Referral Case to Dr. Soetomo Hospital during 2019-2020

Table 1. Characteristics of Post Obstetric Surgery Referral Cases with Surgical Complications to Dr. Soetomo Hospital during 2019-2020

\begin{tabular}{|c|c|c|c|}
\hline Characteristics & $\begin{array}{l}2019 \\
\text { n (\%) }\end{array}$ & $\begin{array}{l}2020 \\
\text { n }(\%)\end{array}$ & $\begin{array}{l}\text { Total } \\
\text { n (\%) }\end{array}$ \\
\hline \multicolumn{4}{|l|}{ Referrals area origin } \\
\hline - Surabaya & $1(7,7 \%)$ & $5(35,71 \%)$ & $6(22,2 \%)$ \\
\hline - Outside Surabaya & $12(92,3)$ & $9(64,29 \%)$ & $21(77,8 \%)$ \\
\hline \multicolumn{4}{|l|}{ Referring hospital } \\
\hline - General Hospital & $4(30,7 \%)$ & $2(14,28 \%)$ & $6(22,2 \%)$ \\
\hline - $\quad$ Private Hospital & $8(61,53 \%)$ & $8(57,14 \%)$ & $16(59,25 \%)$ \\
\hline - Maternity hospital & $1(7,77 \%)$ & $4(28,58 \%)$ & $5(18,55 \%)$ \\
\hline \multicolumn{4}{|l|}{ Patient age } \\
\hline$-\quad<20$ years old & $1(7,7 \%)$ & $0(0 \%)$ & $1(3,7 \%)$ \\
\hline - $\quad 21-35$ years old & $9(69,23 \%)$ & $11(78,57 \%)$ & $20(74,07 \%)$ \\
\hline$>35$ years old & $3(23,07)$ & $3(21,43 \%)$ & $6(22,23 \%)$ \\
\hline \multicolumn{4}{|l|}{ Parity } \\
\hline Nulliparity & $5(38,46 \%)$ & $2(14,28 \%)$ & $7(25,94 \%)$ \\
\hline Primiparity & $1(7,69 \%)$ & $5(35,72 \%)$ & $6(22,22 \%)$ \\
\hline - Multiparity & $7(53,85 \%)$ & $7(50 \%)$ & $14(51,84 \%)$ \\
\hline \multicolumn{4}{|l|}{ Obesity status } \\
\hline$-\quad$ Not Obese $(\mathrm{BMI}<25)$ & $4(30,76 \%)$ & $6(42,86 \%)$ & $10(37,03 \%)$ \\
\hline - $\quad$ Overweight (BMI 25-29.9) & $8(61,54 \%)$ & $4(28,57 \%)$ & $12(44,44 \%)$ \\
\hline - $\quad$ Obesity $($ BMI $>30)$ & $1(7,7 \%)$ & $4(28,57 \%)$ & $5(18,53 \%)$ \\
\hline \multicolumn{4}{|l|}{ Patient's condition } \\
\hline - Decreased GCS & $3(23,07 \%)$ & $3(21,43 \%)$ & $6(22,22 \%)$ \\
\hline - Use of ventilator & $3(23,07 \%)$ & $2(14,28 \%)$ & $5(18,51 \%)$ \\
\hline - $\quad$ Hypovolemic shock & $7(53,84 \%)$ & $5(35,71 \%)$ & $12(44,44 \%)$ \\
\hline Anemia & $13(100 \%)$ & $12(85,71 \%)$ & $25(92,6 \%)$ \\
\hline - $\quad$ Prolonged hemostatic function & $5(38,46 \%)$ & $8(57,14 \%)$ & $13(48,15 \%)$ \\
\hline Thrombocytopenia & $5(38,46 \%)$ & $4(28,57 \%)$ & $9(33,33 \%)$ \\
\hline - Acute renal impairment & $4(30,76 \%)$ & $4(28,57 \%)$ & $8(29,62 \%)$ \\
\hline \multicolumn{4}{|l|}{ Post operation to complication diagnosis-time } \\
\hline$-\quad<=1$ hour & $5(38,46 \%)$ & $2(14,28 \%)$ & $7(25,94 \%)$ \\
\hline $2-3$ hours & $4(30,76 \%)$ & $7(50 \%)$ & $11(40,74 \%)$ \\
\hline 4-6 hours & $3(23,07 \%)$ & $1(7,15 \%)$ & $4(14,81 \%)$ \\
\hline$-\quad>6$ hours & $1(7,7 \%)$ & $4(28,57 \%)$ & $5(18,51 \%)$ \\
\hline \multicolumn{4}{|l|}{ Referral Indication } \\
\hline - Internal bleeding & $8(61,53 \%)$ & $9(64,3 \%)$ & $17(63 \%)$ \\
\hline Postpartum hemorrhage & $3(23,07 \%)$ & $1(7,14 \%)$ & $4(14,8 \%)$ \\
\hline - $\quad$ Medical bleeding & $2(15,4 \%)$ & $0(0 \%)$ & $2(7,4 \%)$ \\
\hline - $\quad$ Urinary tract injury & $0(0 \%)$ & $2(14,28 \%)$ & $2(7,4 \%)$ \\
\hline - Post bladder repair & $0(0 \%)$ & $2(14,28 \%)$ & $2(7,4 \%)$ \\
\hline \multicolumn{4}{|l|}{ Referral time } \\
\hline$-\quad<=1$ hour & $0(0 \%)$ & $1(7,14 \%)$ & $1(3,71 \%)$ \\
\hline - $\quad 2-3$ hours & $5(38,46 \%)$ & $6(42,86 \%)$ & $11(40,74 \%)$ \\
\hline - $\quad 4-6$ hours & $5(38,46 \%)$ & $4(28,57 \%)$ & $9(33,33 \%)$ \\
\hline$-\quad>6$ hours & $3(23,08 \%)$ & $3(21,43 \%)$ & $6(22,22 \%)$ \\
\hline \multicolumn{4}{|l|}{ Type of operations at reffering hospital } \\
\hline - Elective & $2(15,4 \%)$ & $3(21,43 \%)$ & $5(18,51 \%)$ \\
\hline - $\quad$ Emergency & $10(76,9 \%)$ & $11(78,57 \%)$ & $21(77,78 \%)$ \\
\hline - Semiacute & $1(7,7 \%)$ & $0(0 \%)$ & $1(3,71 \%)$ \\
\hline \multicolumn{4}{|l|}{ Management at Dr. Soetomo hospital } \\
\hline - Relaparotomy & $12(92,3 \%)$ & $11(78,6 \%)$ & $23(85,1 \%)$ \\
\hline Conservative & $1(7,7 \%)$ & $3(21,4 \%)$ & $4(14,9 \%)$ \\
\hline
\end{tabular}


Most of the referrals came from private hospitals and from outside the Surabaya area $(77,7 \%)$. The financing used by patients was government insurance (BPJS) (92,5\%). Patients referred were in 21-35 years (74,07\%). The most common patients were multiparity in 14 cases $(51.85 \%)$, and nulliparity was also found in $25,9 \%$ of cases. Obesity was found in $18,5 \%$ of patients. Time needed from post operation to complication diagnosis was 2-3 hours in 11 cases (40,74\%). The most common referral indication was internal bleeding in 17 cases $(62,9 \%)$, with the most common referral time was $2-3$ hours in 11 cases $(40,7 \%)$. Some cases need longer referral time, had arrived in Soetomo hospital more than 6 hours in 6 cases $(22,2 \%)$. The condition of the patients when they arrived included a decrease of GCS in 6 patients, ventilator use in 5 patients, and hypovolemic shock in 12 patients. Complications of anemia $(\mathrm{Hb}<10)$ were found in 25 cases $(92,59 \%)$, thrombocytopenia (platelet $<100,000$ ) in 9 cases, prolonged hemostatic function in 13 cases, and acute renal impairment in 8 cases.

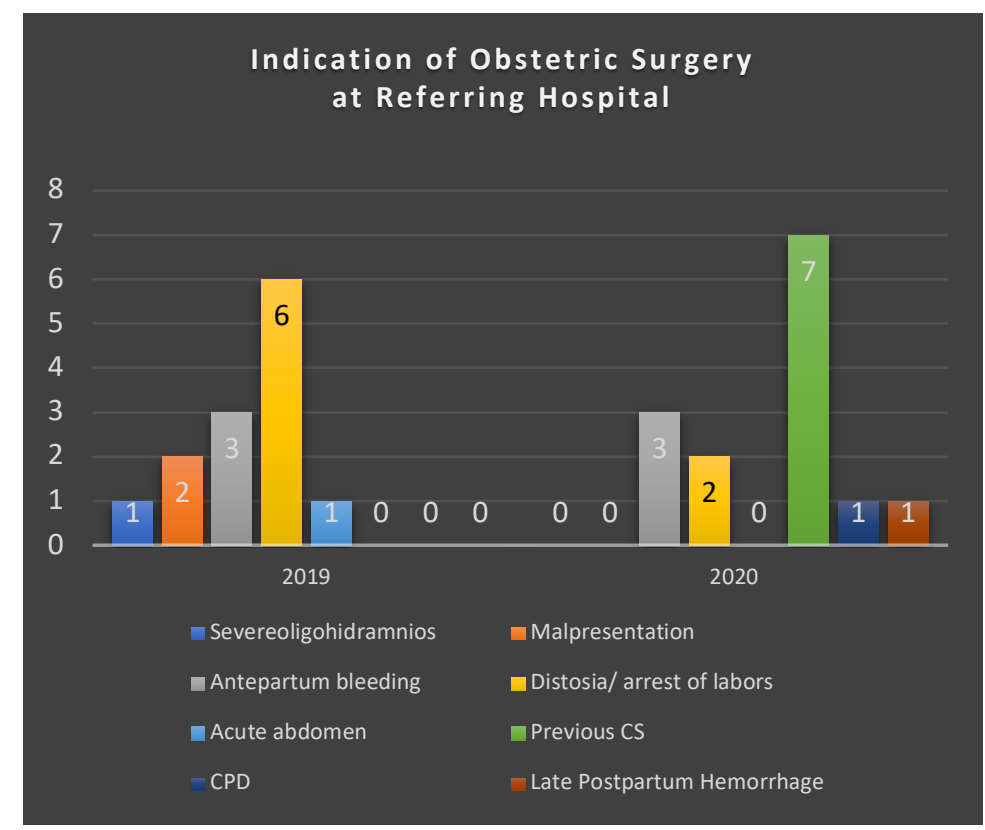

Figure 2. Indication of Obstetric Surgery at Referring Hospital

The most common indications of surgery at referring hospital were the arrest of labors in 6 cases $(46,1 \%)$ in 2019 and previous C-Section in 7 cases (50\%) in 2020. Most of surgery that proceeded in referring hospital were emergency C-section (77,78\%).

Twenty-seven post obstetric surgery referral cases with surgical complications to Dr Soetomo hospital were recorded, and 23 cases $(85,1 \%)$ of them underwent relaparotomy. The most findings during relaparotomy were a uterine problem $(52,5 \%)$, consist of $17,5 \%$ bleeding from the corner stitch of uterine incision, $10 \%$ lower uterine segment dehiscence and $10 \%$ of uterine atony. Another finding was hematoma (22,5\%), with the most findings was retroperitoneal hematoma in $10 \%$ cases. 
Table 2. Relaparotomy Findings in Post Obstetric Surgery Referral Cases with Surgical Complications to Dr. Soetomo General Teaching Hospital during $2019-2020$

\begin{tabular}{|c|c|}
\hline Relaparotomy findings at RSDS & Total \\
\hline Vascular Tearing & $5(12,5 \%)$ \\
\hline - Ovarian artery & $2(5 \%)$ \\
\hline - $\quad$ Uterine artery & $3(7,5 \%)$ \\
\hline - Inferior epigastric artery & $1(2,5 \%)$ \\
\hline Hematoma & $9(22,5 \%)$ \\
\hline - $\quad$ Rectus sheath & $1(2,5 \%)$ \\
\hline - $\quad$ Mesosalpinx & $1(2,5 \%)$ \\
\hline - $\quad$ Parametrium & $2(5 \%)$ \\
\hline - $\quad$ Plica vesicouterine & $1(2,5 \%)$ \\
\hline - $\quad$ Retroperitoneal & $4(10 \%)$ \\
\hline Urinary Tract Injury & $5(12,5 \%)$ \\
\hline - $\quad$ Bladder rupture & $3(7,5 \%)$ \\
\hline - $\quad$ Adhesion uterine and bladder & $1(2,5 \%)$ \\
\hline - $\quad$ Ligated ureter & $1(2,5 \%)$ \\
\hline Uterine Problems & $21(52,5 \%)$ \\
\hline - Uterine atony & $4(10 \%)$ \\
\hline - $\quad$ Bleeding from corner stich of uterine incision & $7(17,5 \%)$ \\
\hline - $\quad$ Lower segment uterine dehiscene & $4(10 \%)$ \\
\hline - $\quad$ Uterine ruptured & $2(5 \%)$ \\
\hline - Unstitched of B-lynch suture & $2(5 \%)$ \\
\hline - $\quad$ Bleeding from vaginal stomp & $2(5 \%)$ \\
\hline Total Findings & $40(100 \%)$ \\
\hline
\end{tabular}

Table 3. Surgical Procedures during Relaparotomy of Referral Case Post Obstetric Surgery with Surgical Complications to Dr. Soetomo General Teaching Hospital during 2019 - 2020

\begin{tabular}{|c|l|}
\hline \multicolumn{1}{|c|}{ Surgery } & \multicolumn{1}{c|}{ Amount } \\
\hline Vascular Ligation & $10(30,3 \%)$ \\
$-\quad$ Ligation Epigastric artery & $1(3,03 \%)$ \\
$-\quad$ Ligation Uterine artery & $3(9,09 \%)$ \\
$-\quad$ Ligation Hypogastric artery & $5(15,15 \%)$ \\
$-\quad$ Ligation Ovary artery & $1(3,03 \%)$ \\
\hline Hysterectomy & $14(42,42 \%)$ \\
$-\quad$ Supra Vaginal Hysterectomy & $10(30,3 \%)$ \\
$-\quad$ Total Abdominal Hysterectomy & $4(12,12 \%)$ \\
\hline Repair lower uterine segment suture & $3(9,09 \%)$ \\
\hline Uterine Compression Suture & $1(3,03 \%)$ \\
\hline Trachelectomy & $2(6,06 \%)$ \\
\hline Bladder Repair & $1(3,03 \%)$ \\
\hline Ureteral Ligation Release & $1(3,03 \%)$ \\
\hline Abdominal Tampons & $1(3,03 \%)$ \\
\hline Total & $\mathbf{3 3 ( 1 0 0 \% )}$ \\
\hline
\end{tabular}

Most of the procedures performed during relaparotomy were hysterectomy $(42,42 \%)$, including total abdominal hysterectomy $(12,12 \%)$, supra vaginal hysterectomy (30,3\%) and vascular ligation $(30,3 \%)$, with the most ligation done on hypogastric artery $(15,15 \%)$. 


\section{Discussion}

The incidence of relaparotomy of obstetric surgery that originally performed at Dr. Soetomo General Teaching Hospital during 2019-2020 was 0,99\%. There were 8 cases of relaparotomy from 806 caesarean sections performed ( 6 cases in 2019 and 2 cases in 2020). This number is higher than the global relaparotomy rate $(0,12 \%-0,72 \%)$ (Peker et al., 2019). However, it is still within the normal range compared to other studies, and relaparotomy ranged from 1-4,4\% (Krisna et al., 2018) and 1-1,6\% after the first surgery (Patel et al., 2017). The most common indications for first surgery were placenta accreta ( 3 cases), antepartum bleeding ( 2 cases), twice previous caesarean section ( 1 case), cardiac cases with Eisenmenger syndrome (1 case), and pregnancy with suspected malignant ovarian tumour (1 case). The most common indications for relaparotomy were suspicion of internal bleeding ( 3 cases), postpartum haemorrhage ( 3 cases), and burst abdomen ( 2 cases), maternal death found in 1 case with postpartum hemorrhage on Eisenmenger syndrome patient.

In the other hand, incidence of relaparotomy was higher in post obstetric surgery referral cases to Dr. Soetomo General Teaching Hospital as tertiary hospital in Indonesia. We found 70 post obstetric surgery referral cases (27 cases in 2019 and 43 cases in 2020). Among these cases, 38,57\% (13 cases in 2019 and 14 cases in 2020) were post obstetric surgery referrals with surgical complications requiring further intervention such as relaparotomy in $85,1 \%$ (12 cases in 2019 and 11 cases in 2020). There was one death case of post-obstetrical referral case with surgical complications that performed relaparotomy caused by septic shock.

Most Referrals came from outside the city where tertiary hospital lies. Most of the referrers were private hospitals with limited facilities and infrastructure for intensive care, blood availability, and specialist doctors from related divisions. One peripheral hospital referred post obstetric surgery patients with complications four times in two years, mostly paying the hospital fee with government insurance (BPJS). Small and limited insurance may also be one reason for their referral to a tertiary hospital, especially for complicated cases that need another operative procedure such as relaparotomy and intensive care management for days.

Among the patients, 74,07\% are women in productive age. Most of them are multiparity (51,85\%). Average BMI was $27,3 \mathrm{~kg} / \mathrm{m}^{2}$, twelve of them were overweight, five were obese, and three people were third-grade obese (BMI $>40$ ). Hypovolemic shock (tachycardia and hypotension) was found in 44,4\% of cases. Some patients also come with inferior conditions, including decreased consciousness (GCS point) and ventilator use. Other complications that occurred in prereferral hospitals due to massive bleeding are anemia, thrombocytopenia, hypoalbumin prolonged hemostatic function, and acute renal impairment. A total of 92,6\% (25 of 27 cases) of the patients had anaemia, and the lowest hemoglobin level was 2,8 g/dl. Patients with thrombocytopenia were found in 33,33\% ( 9 out of 27 cases), and the lowest platelet level was 26,000/mm3. Hypoalbumin (albumin below three $\mathrm{g} / \mathrm{dl}$ ) was found in $22,2 \%$ of cases, with the lowest level of albumin was $1.1 \mathrm{~g} / \mathrm{dl}$. Prolonged hemostatic function was found in $48,15 \%$ of cases with suspicion of DIC, and $29,62 \%$ of patients had acute renal impairment. Most cases (40,74\%) took 2-3 hours to arrive at Dr. Soetomo General Teaching Hospital. We found 6 cases $(22,22 \%)$ even arrived more than 6 hours since it was decided to be referred. It was caused by the distance of referring hospitals that were far from Dr. Soetomo General Teaching Hospital, late family decision making, counselling and education from health workers about the patient's condition, administrative processes, and the availability of ambulances or transportation to do the referral.

Most of surgery that proceeded in referring hospital were emergency caesarean section $(77,78 \%)$ due to various indications. The most typical indication of surgery at the referring hospital in 2019 was the arrest of labors. This result is consistent with a study in a tertiary hospital in Bangladesh that $40 \%$ of indications for 
caesarean section with relaparotomy cases are arrest of labors (Biswas et al., 2012). In 2020, the most indications for surgery were previous caesarean sections by $50 \%$, which is consistent with the study from Gedikbasi et al which found that the risk of relaparotomy will increase by 14,9 higher on three times previous C-section (Gedikbasi et al., 2008). In other research, it was found that $94,12 \%$ of patients who underwent relaparotomy were cases of a $\mathrm{C}$-section performed previously in an emergency, and the most common indications of surgery were previous C-section, fetal distress and arrest of labors (Devi and Ratna, 2019). The high emergency caesarean section rate will increase the risk of relaparotomy four times $(\mathrm{p}=0.05)$ (Seal et al., 2007). The decision to do relaparotomy after caesarean section is based on the findings of vaginal bleeding, tachycardia and hypotension, decreased haemoglobin level, distended abdomen with free fluid on ultrasound examination, and anuria (Peker et al., 2019). Relaparotomy cases in this study were performed by suspicion of internal bleeding in $62,9 \%$ of cases and postpartum hemorrhage in $14,8 \%$ of cases.

Most referral reasons were limited facilities and resources to manage internal bleeding in 17 cases $(62,96 \%)$, postpartum haemorrhage in 4 cases $(14,81 \%)$, suspicion of urinary tract injury in 2 cases $(7,4 \%)$, and medical bleeding in 2 cases $(7,4 \%)$.

The most common findings during relaparotomy were 52,5\% uterine problem and 22,5\% hematoma. Uterine problems consist of uterine atony, bleeding from corner stitch uterine incision, lower uterine segment dehiscence and hematoma, uterine rupture, loose B-lynch suture, and bleeding from a vaginal stump. Bleeding from corner stitch of uterine incision found in $17,5 \%$. The most common intra abdomen hematoma was retroperitoneal hematoma. Another finding was vascular injury such as uterine artery injury due to extension of the lower uterine segment incision. This finding can be reduced by using excellent and careful surgical techniques, avoiding excessively inferior uterine incisions and exteriorizing the uterus when suturing the lower segment of the uterine. Carefully take out the baby's head. Vascular tears can be treated with ligation, hemostatic sutures can be performed to stop the bleeding area and hematoma, or if it has not stopped, uterine ligation artery or internal iliac artery can be done in cases with adhesive placenta (Field and Haloob, 2016) —inferior epigastric artery tear caused by trauma when cutting the rectus muscle (Senturk et al., 2016 ). Ovaries artery may be injured during the sterilization procedure. Most of the surgical procedures performed during relaparotomy were hysterectomy (total abdominal hysterectomy in $12.12 \%$ cases and supra vaginal hysterectomy in $30,3 \%$ cases), and vascular ligation (30,3\%) with the most common vascular ligated was hypogastric artery $(15,15 \%)$. One post obstetric surgery referral case with complications of bladder rupture who underwent relaparotomy died of septic shock.

Surgical complications are possible in every operation, including obstetric surgery such as caesarean section. The procedure is often performed in an emergency condition, and there are anatomical and physiological changes in pregnant women and a higher patient's body mass index, which are risks factors for increasing surgical errors. Prevention of surgical errors will reduce the occurrence of surgical complications and prevent patients from morbidity and mortality. Among all causes, the most common cause of near-miss and maternal death is postpartum hemorrhage which is preventable in about $47 \%$ of cases (Benimana et al., 2017). Delays in diagnosis and therapy and human error are responsible for around 41,3\% of near-miss cases. Lack of availability of medicines and blood and ICU facilities are responsible for around 5,8\% of maternal mortality cases, of which 2,5\% are preventable (Benimana et al., 2017). Most of the cases requiring relaparotomy were C-section cases with an indication of a history of previous C-Section and arrest of labors. The causes of relaparotomy are primarily the result of surgical errors. Selection of the correct surgical technique, good hemostasis, and careful closure of the operating field will prevent the risk of relaparotomy after cesarean section. Closed monitoring of all postoperative patients will define early detection of surgical complications such as postpartum hemorrhage 
and internal bleeding so the patient can be treated early and prevent maternal morbidity and mortality (Rawal and Rana, 2012). The following things can be done to reduce the risk of relaparotomy after caesarean section:

- Ensure that the uterine suture is suitable and does not seep, especially at both ends of the uterine incision. Better to make a corner stitch

- Ensure that there is no extension of the uterine incision. It is better to exteriorize the uterine

- Ensure no residual bleeding, clots, or active bleeding sources in the intraperitoneal cavity by washing the abdominal cavity with normal saline.

- Ensure that when closing each layer of the operating field, there is no seeping bleeding or hematoma formation

- Ensure that the patients hemodynamic is good before closing the operating field to ensure that there is no ongoing loss

- If a surgeon performs a cesarean hysterectomy and has doubts that there is still micro bleeding of unknown origin, they can consider installing a drain as a tool for observation.

Tachycardia, hypotension, and decreased urine output are the earliest signs of possible internal or postpartum hemorrhage, which eventually lead to the possibility of relaparotomy. These things should be monitored closely in postoperative patients to avoid maternal morbidity and mortality due to delayed relaparotomy.

\section{Conclusion}

During 2019-2020 there were 27 cases of post obstetric surgery referral cases from peripheral hospital and 23 cases $(38,57 \%)$ of them performed relaparotomy in Dr. Soetomo General Teaching Hospital. Indications of previous surgery that have highest risk factor for relaparotomy were previous C-Section and arrest of labors. Relaparotomy was performed by suspicion of internal bleeding. Most common relaparotomy finding were bleeding from corner stitch of uterine incision and retroperitoneal hematoma. Most common procedure performed during relaparotomy were hysterectomy and vascular ligation. Management of these surgery complications didn't need special skill. Careful procedure, closed monitoring on post-operative condition, accurate clinical judgement, time of decision making and adequate facilities will prevent maternal morbidity and mortality.

\section{Ethical Approval}

The research was approved by the Human Research Ethics Committee, Dr. Soetomo General Teaching Hospital, with approval number 0538/LOE/301.4.2/VIII/2021.

\section{Conflicts of Interest}

The authors declare that there are no conflicts of interest.

\section{Referrences}

Benimana, C., Small M., \& Rulisa S. 2017. Preventability of Maternal Near Miss and Mortality in Rwanda : A Case Series from the University Teaching Hospital of Kigali (CHUK). PLOS ONE; vol. 13(6).

Biswas, SP, Halder S., \& Shirin FB. 2012. Indication and Outcome of Relaparotomy After Caesarean Section. Bang Med J (Khulna) vol 45. pp. 19-23.

Devi, S., Ratna G. 2019. Relaparotomy After Caesarean Section- A Study in Tertiary Care Hospital. IOSR Journal of Dental and Medical Sciences (IOSR-JDMS). pp. 05-08.

Field, A., Haloob R., 2016. Complications of Caesarean Section. The Obstetrician \& Gynecologist. pp. 265-272.

Gedikbasi A, Akyol A, Asar E. 2008. Re-laparotomy After Cesarean Section: Operative Complications in Surgical Delivery. Arch Gynecol Obstet vol 278(5). pp. 419-425.

Krisna, A., Shivaramegowda S., Kumar A., \& Manjunath S. 2018. Relaparotomy-the Surgeons Nightmare. Indian Journal of Surgery. 
Patel, H., Patel P., \& Shah DK. 2017. Relaparotomy in General Surgery Department of Tertiary Care Hospital of Western India'. International Surgery Journal vol 4. pp. 344-347.

Peker, N., Yavuz M., Aydin E., Ege S., Bademkiran MH \& Karacor T. 2019. Risk Factor for Relaparotomy After Caesarean Section due to Hemorrhage : A Tertiary Center Experience. The Journal of Maternal fetal \& Neonatal Medicine.

Rawal S, Rana A. 2012. Second Intervention in Obstetric Hemorrhage. Journal of the Institute of Medicine vol. 34 (1). pp. 18-24.

Seal SL, Kamilya G, Bhattacharyya SK, Mukherji J, Bhattacharyya AR. 2007. Relaparotomy After Cesarean Delivery: Experience from an Indian Teaching Hospital. Journal of Obstetrics Gynecol Res vol. 33(6). pp. 804-809.

Senturk, MB., Guraslan H., Polat M, Durukan OB. 2016. Postpartum Hemorrhage due to Inferior Epigastric Vein Injury. The Medical Bulletin of Sisli Etfal Hospital Vol 50. 